\title{
Clinical Study \\ Perspectives of CB1 Antagonist in Treatment of Obesity: Experience of RIO-Asia
}

\author{
Changyu Pan, ${ }^{1}$ Hyung Joon Yoo, ${ }^{2}$ and Low-Tone $\mathrm{Ho}^{3,4,5}$ \\ ${ }^{1}$ Department of Endocrinology, Chinese PLA, General Hospital, No. 28, Fuxing Road, Beijing 100853, China \\ ${ }^{2}$ Division of Endocrinology and Metabolism, Department of Internal Medicine, Hangang Sacred Heart Hospital, \\ 94-200, Yeongdeungpo-Dong, Yeongdeungpo-Gu Seoul 150-719, Republic of Korea \\ ${ }^{3}$ Department of Medical Research \& Education, Taipei Veterans General Hospital, No. 201, Sec. 2, Shih-Pai Road, Taipei 112, Taiwan \\ ${ }^{4}$ Division of Endocrinology \& Metabolism, Taipei Veterans General Hospital, No. 201, Sec. 2, Shih-Pai Road, Taipei 112, Taiwan \\ ${ }^{5}$ Institute of Physiology, National Yang-Ming University, No. 155, Li-Nong Street, Taipei 112, Taiwan
}

Correspondence should be addressed to Low-Tone Ho, ltho@vghtpe.gov.tw

Received 10 June 2010; Accepted 9 November 2010

Academic Editor: S. B. Heymsfield

Copyright (c) 2011 Changyu Pan et al. This is an open access article distributed under the Creative Commons Attribution License, which permits unrestricted use, distribution, and reproduction in any medium, provided the original work is properly cited.

\begin{abstract}
Rimonabant, a selective cannabinoid-1 (CB1) receptor antagonist, has been shown to reduce weight and enhance improvements in cardiometabolic risk parameters in Western populations. This study assessed these effects of rimonabant in Asian population. A total of 643 patients (BMI $25 \mathrm{~kg} / \mathrm{m}^{2}$ or greater without diabetes) from China, Republic of Korea, and Taiwan were prescribed a hypocaloric diet $(600 \mathrm{kcal} /$ day deficit $)$ and randomized to rimonabant $20 \mathrm{mg}(n=318)$ or placebo $(n=325)$ for $9 \mathrm{months}$. The primary efficacy variable was weight change from baseline after 9 months of treatment. Results showed that rimonabant group lost more weight than placebo, (LSM \pm SEM of $-4.7 \pm 0.3 \mathrm{~kg}$ vs. $-1.7 \pm 0.3 \mathrm{~kg}, P<.0001)$. The $5 \%$ and $10 \%$ responders were 2 or 3 folds more in the rimonabant group (53.0\% vs. $20.0 \%$ and $21.5 \%$ vs. $5.7 \%$, resp.) $(P<.0001)$. Rimonabant also significantly increased HDL-cholesterol, decreased triglycerides and waist circumference,by $7.1 \%, 10.6 \%$, and $2.8 \mathrm{~cm}$, respectively $(P<.0001)$. This study confirmed the comparable efficacy and safety profile of rimonabant in Asian population to Caucasians. Owing to the recent suspension of all the $\mathrm{CB} 1$ antagonists off the pharmaceutical market for weight reduction in Europe and USA, a perspective in drug discovery for intervening peripheral CB1 receptor in the management of obesity is discussed.
\end{abstract}

\section{Introduction}

Overweight and obesity, a global phenomenon, affects more than 1 billion adults, with 300 million being clinically obese [1]. With changing life styles and dietary patterns, obesity is rapidly increasing in epidemic proportions globally. In the national nutritional surveys of the 3 countries that participated in the RIO-Asia study, the obesity prevalence rates were at $14.7 \%$ in China [2], $26.6 \%$ in Taiwan [3], and $30.6 \%$ in Korea [4] in the year 2001-2002.

Obesity is a complex metabolic disorder characterized by an imbalance in energy homeostasis [5], abnormal development of adipose tissue, and deregulation of hormones and cytokines including adipocytokines [6]. This chronic metabolic imbalance is associated with comorbidities such as cardiovascular disorders [7], hypertension [8], sleep apnea
[9], diabetes mellitus [1], and certain types of cancer [10] and related morbidity/mortality. Besides weight loss and favorable cardiometabolic profile [11], pharmacological interventions for obesity should address reduction in abdominal obesity and lower the risk of developing diabetes mellitus.

$\mathrm{G}$ protein-coupled cannabinoid receptor, $\mathrm{CB}-1$ of the endocannabinoid system (ECS), plays a crucial role in regulating feeding pattern, lipid metabolism, and energy homeostasis. CB-1 receptors are located in the central nervous system and peripheral tissues including adipocytes, pancreas, gut, liver, and muscle [12]. Rimonabant is a selective CB-1 antagonist drug to be developed for weight loss. Results of in vitro experiments have suggested the involvement of fourth and fifth transmembrane domains of the CB-1 receptor for high-affinity binding of rimonabant $[13,14]$. Rimonabant 
has been shown to exert a peripheral effect on food intake by regulating Acrp30 (i.e., adiponectin) and insulin, hormones involved in lipid and glucose metabolism, respectively [5]. The mechanism of the long-lasting weight loss through rimonabant may be associated with an increase in energy expenditure and/or metabolic activities $[5,15]$.

Animal studies $[16,17]$ and human trials have demonstrated the efficacy of rimonabant in inducing weight loss and improving dyslipidemia and insulin sensitivity. The RIO-Europe [18] and RIO-North America [19] clinical trials studied the weight loss in obese or overweight Caucasians treated with $20 \mathrm{mg}$ rimonabant. At the end of a 1-year period, the weight loss was significantly greater in patients treated with rimonabant $(-6.3$ to $-6.6 \mathrm{~kg} ; P<.001$ versus placebo, -1.6 to $-1.8 \mathrm{~kg}$ ). The proportion of patients who achieved $5 \%$ or greater decrease in body weight was $48.6-50.9 \%$ while a $10 \%$ or greater decrease was noted in $25.2-27.4 \%$ patients. A reduction in waist circumference $(3.6 \mathrm{~cm})$ and triglycerides $(13.2 \%)$, as well as an increase in HDL-cholesterol (7.2\%), was also observed in the rimonabant group. After 2 years of treatment with $20 \mathrm{mg}$ rimonabant, the weight loss was maintained at $7.4 \mathrm{~kg}$. Similar results were observed in the RIO-Lipid study [20] which analyzed the efficacy of rimonabant $20 \mathrm{mg}$ in overweight or obese Caucasians with dyslipidemia. A significant suggestion of the study was that in addition to weight reduction, rimonabant also mobilized abdominal fat and improved cardiovascular risk profile. Furthermore, although the adiponectin-elevating effect was indirect, it was independent of weight loss.

The efficacy of rimonabant in Asian ethnicity has not yet been evaluated. Evidence shows that the incidence of obesity is increasing rapidly in Asian countries [1,21,22]. As stated above, Asian populations have a greater body fat content at a lower body mass index (BMI) compared with Caucasians $[23,24]$. Consequently, obesity-related metabolic disorders like dyslipidemia, hypertension, and type 2 diabetes are more frequently observed at lower BMI in Asians than in Caucasians [22]. Hence, the WHO has redefined the classification of obesity based on BMI in Asians. The BMI cutoff was lowered in Asians to $\geq 23.0 \mathrm{~kg} / \mathrm{m}^{2}$ for overweight and $\geq 25.0 \mathrm{~kg} / \mathrm{m}^{2}$ for obesity compared to $25-30 \mathrm{~kg} / \mathrm{m}^{2}$ for overweight and $\geq 30 \mathrm{~kg} / \mathrm{m}^{2}$ for obesity in Caucasians $[1,22,25]$.

The RIO-ASIA study evaluated the efficacy and safety of rimonabant $20 \mathrm{mg}$, along with a hypocaloric diet, in reducing weight and improving cardiometabolic risk factors in obese Asian population.

\section{Methods and Procedures}

2.1. Study Design. This phase 3, randomized, double-blind, placebo-controlled, parallel-group, multinational study was carried out in 32 centers in China $(n=240)$, Republic of Korea $(n=200)$, and Taiwan $(n=203)$ between April 2006 and April 2007.

After a screening period of 7 to 14 days, obese patients were randomized in a $1: 1$ ratio to treatment with rimonabant $20 \mathrm{mg}(n=318)$ once daily or placebo $(n=325)$ for a 9-month period. Randomization was stratified based on BMI status at baseline as 25 to $27 \mathrm{~kg} / \mathrm{m}^{2}$ or $>27 \mathrm{~kg} / \mathrm{m}^{2}$.
Follow-up visits were scheduled every 28 days throughout the study duration. Study participants were prescribed at baseline a hypocaloric diet for the study duration. The calorie requirement was calculated based on basal metabolism rate and physical activity, from which $600 \mathrm{kcal} /$ day was subtracted to calculate the recommended diet. A food intake assessment was carried out on day 84, day 168, and day 252 from diet diary entries. The protocol, approved by the Institutional Review Boards/Ethics Committees for each centre, was conducted in compliance with the Helsinki Declaration and with an independent, unblinded data monitoring committee. All patients provided written informed consent.

2.2. Patients. Eligible patients were aged $\geq 18$ years with a BMI $\geq 25 \mathrm{~kg} / \mathrm{m}^{2}$. Exclusion criteria were a body weight fluctuation of at least $5 \mathrm{~kg}$ in the previous 3 months, a systolic blood pressure $>165 \mathrm{~mm} \mathrm{Hg}$ and/or diastolic blood pressure $>105 \mathrm{~mm} \mathrm{Hg}$ at screening and baseline, presence of type 1 or type 2 diabetes, presence of any clinically significant disorders (endocrine/metabolic/neurological/psychological disorders; presence/history of cancer).

2.3. Measures and Assessments. The primary efficacy endpoint was the absolute weight change from baseline (randomization) to 9 months in the intent-to-treat (ITT) population. Secondary efficacy endpoints were waist circumference (as a marker of change in abdominal obesity), high-density lipoprotein (HDL)-cholesterol, triglycerides, fasting insulin, and glucose.

Measurement of body weight was carried out at each visit using a calibrated scale. Based on established protocol [26], 3 waist measurements were taken in centimeters at the midpoint between the lower rib margin and the iliac crest. The variations in these measurements were expected to be $\leq 1.0 \mathrm{~cm}$. Failure to fit within these criteria would lead to a fourth measurement. Metabolic parameters, including glucose, insulin, glycosylated hemoglobin (HbAlc), total cholesterol, low-density lipoprotein (LDL)-cholesterol, HDL-cholesterol, and triglycerides, were measured under fasting conditions on day 84 , day 168 , and day 252 in a central laboratory. Safety assessments consisted of spontaneously reported adverse events, clinical examinations, laboratory tests, vital signs, and electrocardiograms.

2.4. Statistical Analysis. The sample size calculations for the study were derived from the RIO-Europe study and were based on a test to compare the mean change in weight (primary variable) and HDL-cholesterol (secondary confirmatory variable) from baseline between the 2 groups. The calculations of sample sizes were done using the sample size software nQuery Advisor 4.0. Thus with a standard deviation (SD) of $6.5 \mathrm{~kg}, 200$ randomized patients (100 patients/group) were required to detect a mean treatment difference of $3 \mathrm{~kg}$ in weight. For HDL-cholesterol change, with a common SD of $25 \%, 414$ randomized patients (207 patients/group) were required to detect a mean treatment difference of $8 \%$ in HDL-cholesterol. Finally, to fulfill the country/region requirements for the number of exposed 


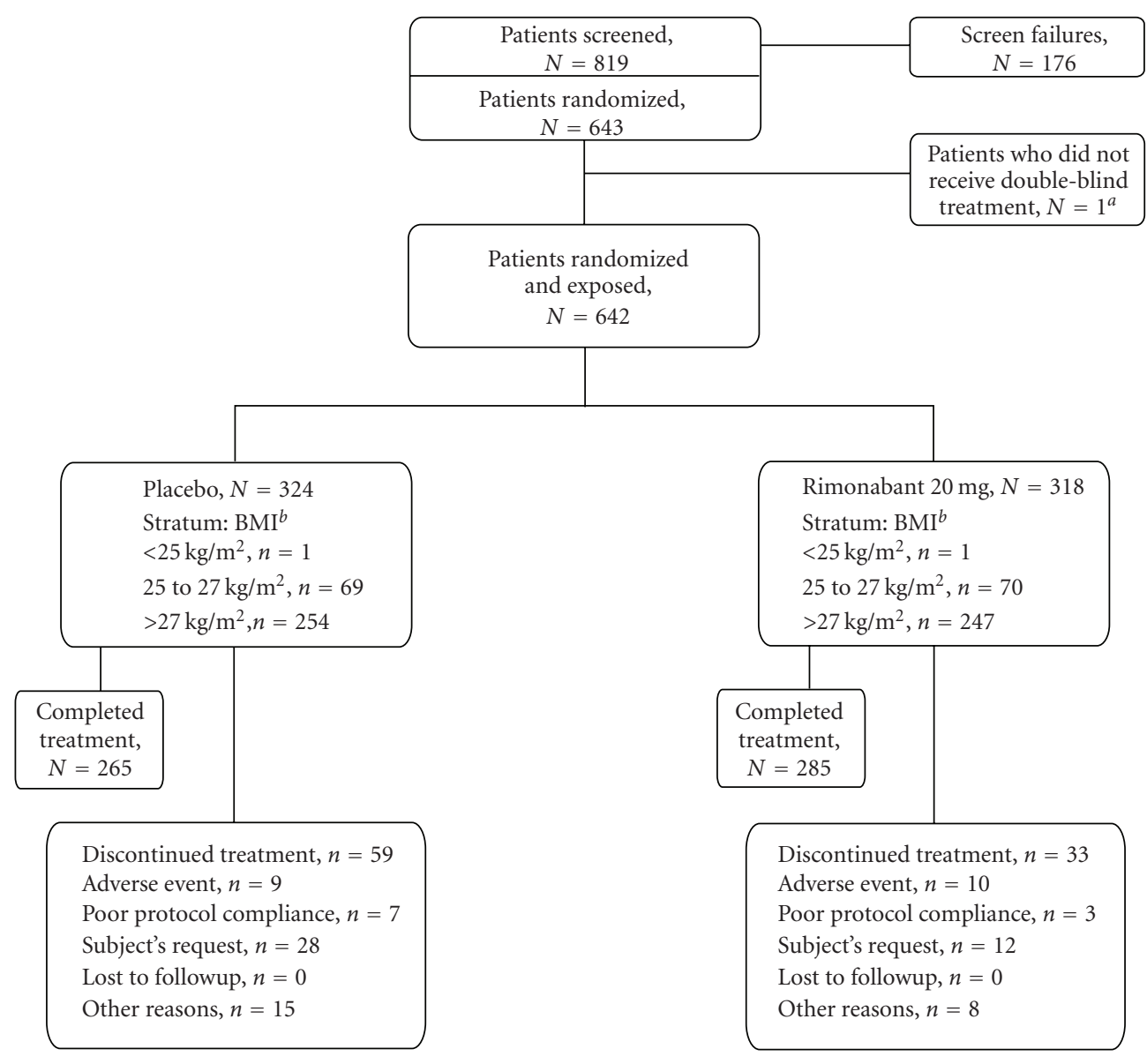

${ }^{a}$ One patient who was randomized to the placebo group was not exposed to the investigational product owing to a diagnosis of pregnancy at the time of randomization.

b Baseline BMI was used.

FIgURe 1: Flow of patients in RIO Asia study.

patients, a total of 640 patients had to be randomized (320 patients/group).

Statistical analysis was performed using SAS version 8.2 or higher. All statistical tests were 2 -sided at the 5\% significance level. Efficacy analyses were performed in ITT population, which consisted of all randomized patients and was the primary population for efficacy analyses.

The absolute change in body weight from baseline to 9 months was analyzed using a 3-way analysis of covariance (ANCOVA) model, which included 3 fixed effectstreatment, country/region, and randomization stratumand 1 covariate, baseline weight. Rimonabant $20 \mathrm{mg}$ was compared with placebo using a Student's $t$-test within the framework of the ANCOVA model. In addition, a 95\% confidence interval (CI) was constructed for the difference in mean absolute weight changes between the groups.

Patients who achieved a $5 \%$ or $10 \%$ reduction in body weight from baseline at 9 months were classified as $5 \%$ or $10 \%$ responders. The proportion of $5 \%$ or $10 \%$ responders in the rimonabant 20-mg group was compared with placebo using a logistic regression model with 3 fixed effects- treatment, country/region, and randomization stratumand 1 covariate, baseline body weight.

Secondary efficacy endpoints were analyzed at 9 months using the ITT population. With the exception of the lipid parameters, continuous secondary efficacy endpoints were assessed as the absolute change from baseline at 9 months. Lipid parameters, except total cholesterol/HDLcholesterol ratio, were assessed as relative change from baseline and analyzed as described for the other secondary end points.

In the efficacy analyses of endpoints for the ITT population, the last observation carried forward method (LOCF) was used to account for missing assessments or patients who prematurely discontinued. These endpoints were replaced by the last available postbaseline on-treatment observation.

\section{Results}

3.1. Patients. A total of 643 patients were randomized ( 318 in the rimonabant $20 \mathrm{mg}$ group and 325 in the placebo group) from 32 centers in China $(n=240)$, Republic 
TABLE 1: Demographic characteristics and comorbidities.

\begin{tabular}{|c|c|c|c|}
\hline & $\begin{array}{l}\text { Placebo } \\
(N=324)\end{array}$ & $\begin{array}{l}\text { Rimonabant } \\
20 \mathrm{mg} \\
(N=318)\end{array}$ & $\begin{array}{l}\text { Overall } \\
(N=642)\end{array}$ \\
\hline \multicolumn{4}{|l|}{ Age (years) } \\
\hline Overall, mean (SD) & $35.3(10.5)$ & $36.7(10.8)$ & $36.0(10.7)$ \\
\hline \multicolumn{4}{|l|}{ Age group, $n(\%)$} \\
\hline$<18$ & 0 & $1(0.3 \%)$ & $1(0.2 \%)$ \\
\hline [18-49] & $294(90.7 \%)$ & $273(85.8 \%)$ & $567(88.3 \%)$ \\
\hline$[50-64]$ & $27(8.3 \%)$ & $41(12.9 \%)$ & $68(10.6 \%)$ \\
\hline$\geq 65$ & $3(0.9 \%)$ & $3(0.9 \%)$ & $6(0.9 \%)$ \\
\hline \multicolumn{4}{|l|}{ Gender, $n(\%)$} \\
\hline Male & $103(31.8 \%)$ & $99(31.1 \%)$ & $202(31.5 \%)$ \\
\hline Female & $221(68.2 \%)$ & $219(68.9 \%)$ & $440(68.5 \%)$ \\
\hline \multicolumn{4}{|l|}{ Country, $n(\%)$} \\
\hline China & $121(37.3 \%)$ & $119(37.4 \%)$ & $240(37.4 \%)$ \\
\hline Republic of Korea & $101(31.2 \%)$ & $99(31.1 \%)$ & $200(31.2 \%)$ \\
\hline Taiwan & $102(31.5 \%)$ & $100(31.4 \%)$ & $202(31.5 \%)$ \\
\hline \multicolumn{4}{|l|}{ Comorbidities, $n(\%)$} \\
\hline Hypertension & $42(13.0 \%)$ & $51(16.0 \%)$ & $93(14.5 \%)$ \\
\hline Dyslipidemia & $73(22.5 \%)$ & $73(23.0 \%)$ & $146(22.7 \%)$ \\
\hline
\end{tabular}

of Korea $(n=200)$, and Taiwan $(n=203)-1$ patient randomized to the placebo group did not receive the study treatment. A higher percentage of patients in the rimonabant $20 \mathrm{mg}$ group $(n=285,89.6 \%)$ completed the study treatment period compared with the placebo group $(n=$ 265, 81.5\%) (Figure 1). 11 patients were excluded from the ITT population ( 1 for nonexposure and 10 for missing postbaseline weight assessment); thus, the ITT population consisted of 632 patients ( 317 and 315 patients on placebo and rimonabant $20 \mathrm{mg}$ groups, resp.). Treatment compliance was similar in both treatment groups: $98.7 \%$ and $96.9 \%$; patients in the rimonabant and placebo groups, respectively, achieved $80 \%$ treatment compliance target (data on file).

Demographic and baseline characteristics were similar between the 2 treatment groups, with equal distribution of patients across treatment in the 3 countries (Tables 1 and 2 ). $14.5 \%$ patients had hypertension, and $22.7 \%$ were dyslipidemic. Mean age was $36 \pm 10.7$ years with more than two thirds of patients being women (68.5\%). Mean BMI was $30.26 \pm 4.23 \mathrm{~kg} / \mathrm{m}^{2}$ with a baseline weight ranged from 54.3 to $161.5 \mathrm{~kg}$ and a mean weight of $81.48 \pm 15.67 \mathrm{~kg}$. Majority of patients $(78.0 \%)$ had BMI $>27 \mathrm{~kg} / \mathrm{m}^{2}$. More than one third of patients had low HDL-cholesterol (34.1\%), high triglycerides (31.3\%), and high LDL-cholesterol $(32.7 \%)$, and $17.4 \%$ had impaired fasting glucose.

3.2. Weight. In the ITT population, weight loss was significantly greater in the rimonabant group (least square (LS) mean \pm SEM: $-4.7 \pm 0.3$ ) than in the placebo group (LS mean \pm SEM: $-1.7 \pm 0.3)$ at 9 months, leading to a placebosubtracted weight loss of approximately $3.0 \mathrm{~kg}(P<.0001)$ (Figure 2(a)). When expressedas a percentage, rimonabant- treated patients lost $6.0 \%$ of their baseline body weight versus $2.3 \%$ in the placebo group.

The percentage of patients who achieved at least a 5\% reduction and $10 \%$ reduction from their baseline body weight at 9 months in the rimonabant 20 -mg group (53.0\% and $20.0 \%$, resp.) was more than 2 -fold and 3 -fold higher compared with the placebo group $(21.5 \%$ and $5.7 \%$, resp.) $(P<.0001)$ in the ITT population (Figure $2(\mathrm{~b}))$.

Treatment with rimonabant resulted in a significant $(P<$ .001) decrease in weight in both BMI strata. In patients with BMI of 25 to $27 \mathrm{~kg} / \mathrm{m}^{2}$ and $>27 \mathrm{~kg} / \mathrm{m}^{2}$, the percentage of weight decrease was $5.61 \%$ and $6.11 \%$, respectively, with rimonabant $20 \mathrm{mg}$ while the corresponding changes in the placebo group were $2.05 \%$ and $2.31 \%$ (Table 3 and Figure 3 ).

3.3. Changes in Secondary Efficacy Variables. At 9 months, the percentage change in HDL-cholesterol revealed a steady increase in both treatment groups (Figure 4(a)). Rimonabant increased HDL-cholesterol by $7.1 \%$ compared with placebo $(P<.0001)$. Rimonabant reduced triglyceride levels by $10.6 \%$ compared with placebo $(P=.0047)$. The mean waist circumference decreased from baseline by 5.93 $\pm 0.33 \mathrm{~cm}$ in the rimonabant $20-\mathrm{mg}$ group compared with $3.2 \pm 0.33 \mathrm{~cm}$ in the placebo group $(-2.8 \mathrm{~cm}$ versus placebo; $P<.0001$ ) (Figure 4(c)). In this nondiabetic population, minimal, nonsignificant changes were observed in fasting glucose and fasting insulin in both groups at 9 months, with, however, a favorable trend for rimonabant $20 \mathrm{mg}$, especially in fasting insulin.

3.4. Safety Events. The incidence of treatment-emergent adverse events (TEAEs) was higher in the rimonabant group 


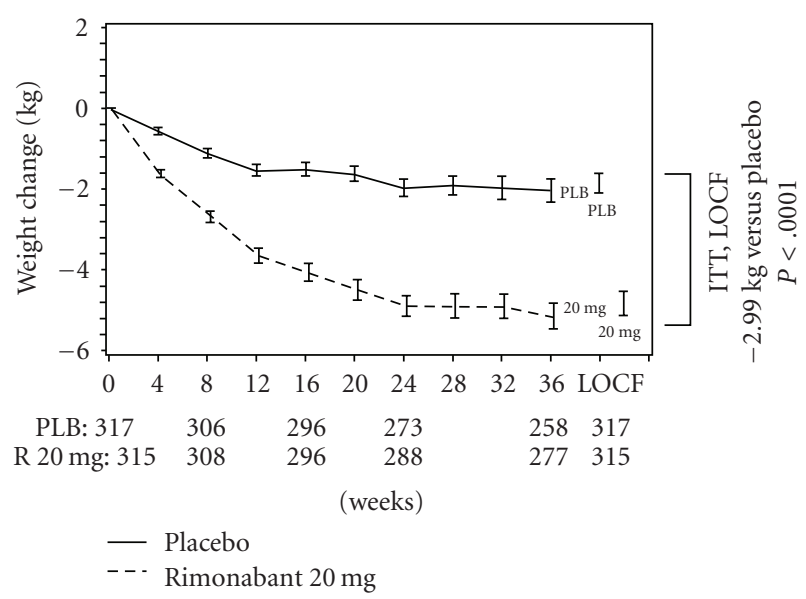

(a)

Weight loss $\geq 5 \%$

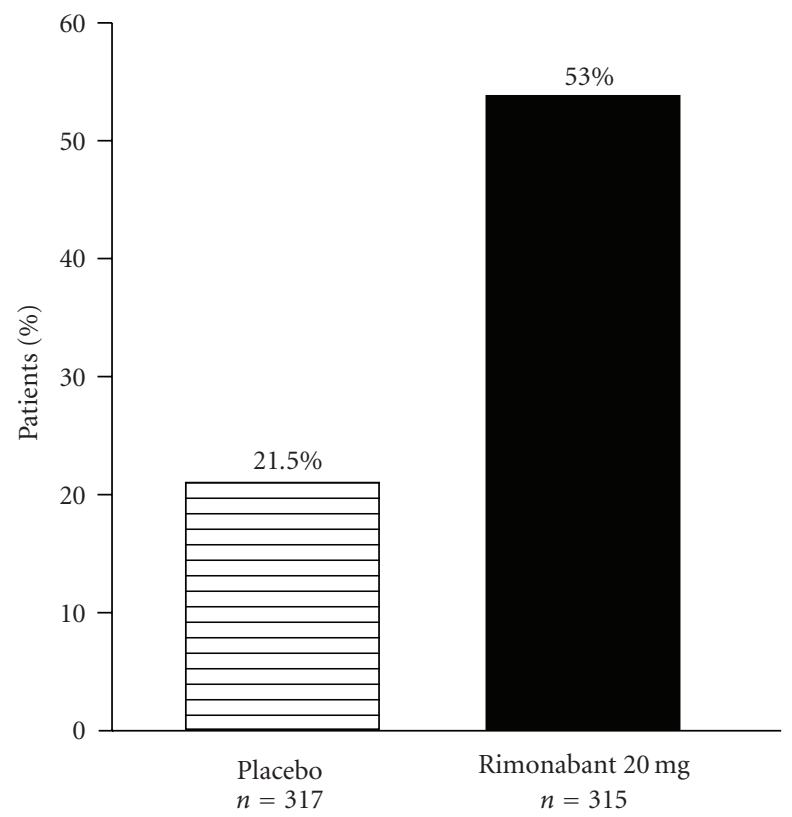

${ }^{\text {a }} P<.0001$ versus placebo.

ITT, intent to treat; LOCF, last observation carried forward; PLB, placebe; R, Rimonabant.
Weight loss $\geq 10 \%$

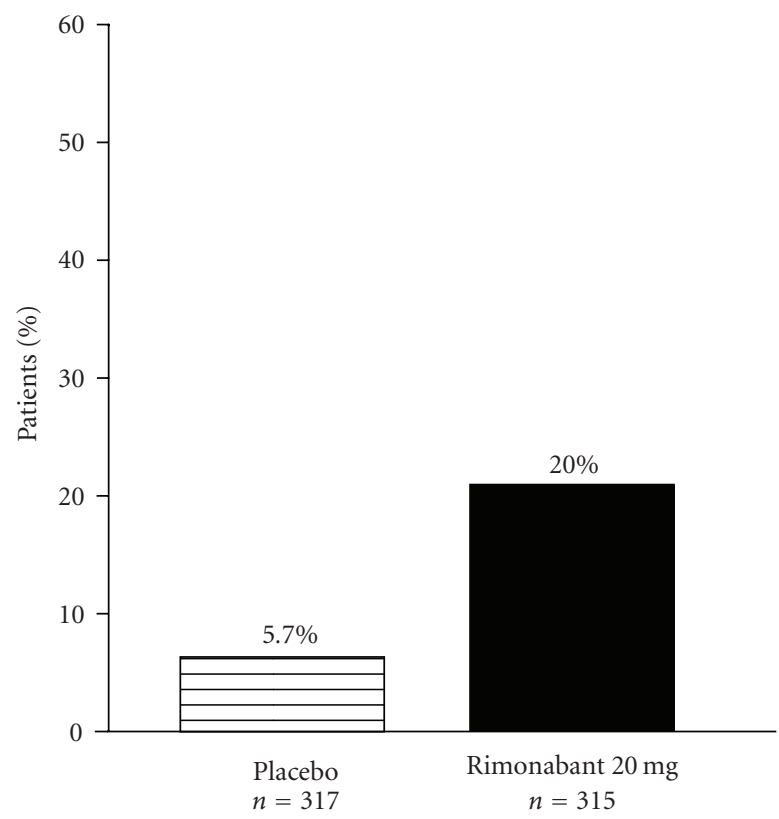

(b)

FIgURE 2: Effect of rimonabant on (a) weight at each visit and at 9 months (b) 5\% and 10\% weight responders.

$(66.0 \%, n=210)$ compared with the placebo group $(56.8 \%, n=184)$ (Table 4$)$. The percentage of patients who permanently discontinued due to TEAEs was low and comparable between the placebo $(2.8 \%, n=9)$ and rimonabant $(3.1 \%, n=10)$ groups. Serious TEAEs were more frequently reported in the placebo group compared with the rimonabant $20 \mathrm{mg}$ group (4.6\% versus $3.1 \%$ ) with no deaths reported during the study period. The most frequent adverse events $(\geq 0.5 \%)$ leading to treatment discontinuation were dizziness in the rimonabant $20 \mathrm{mg}$ group $(0.9 \%$ versus $0.6 \%$ in placebo) and headache $(0.6 \%$ versus $0.0 \%$ in rimonabant $20 \mathrm{mg}$ ) in the placebo group (data on file).

In the rimonabant group (Table 4 ), the common adverse events reported with $a \geq 2 \%$ incidence $(\geq 1 \%$ over placebo patients) were upper respiratory tract infections $(10.7 \%$ versus $9.0 \%)$, nausea $(11.6 \%$ versus $4.0 \%)$, diarrhea $(7.5 \%$ 
TABLE 2: Baseline characteristics: randomized and expose patients.

\begin{tabular}{|c|c|c|c|}
\hline & Placebo $(N=324)$ & Rimonabant $20 \mathrm{mg}(N=318)$ & Overall $(N=642)$ \\
\hline \multicolumn{4}{|l|}{ Weight $(\mathrm{kg})$} \\
\hline Mean (SD) & $82.00(16.40)$ & $80.95(14.90)$ & $81.48(15.67)$ \\
\hline \multicolumn{4}{|l|}{ Waist (cm) } \\
\hline \multicolumn{4}{|l|}{ Male, $n(\%)$} \\
\hline$>90 \mathrm{~cm}$ & $97(94.2 \%)$ & $92(92.9 \%)$ & $189(93.6 \%)$ \\
\hline \multicolumn{4}{|l|}{ Female, $n(\%)$} \\
\hline$>80 \mathrm{~cm}$ & $209(94.6 \%)$ & $211(96.3 \%)$ & $420(95.5 \%)$ \\
\hline \multicolumn{4}{|l|}{$B M I\left(k g / m^{2}\right)$} \\
\hline Mean (SD) & $30.45(4.41)$ & $30.07(4.04)$ & $30.26(4.23)$ \\
\hline \multicolumn{4}{|l|}{ BMI group, $n(\%)$} \\
\hline$<25$ & $1(0.3 \%)$ & $1(0.3 \%)$ & $2(0.3 \%)$ \\
\hline [25-27] & $69(21.3 \%)$ & $70(22.0 \%)$ & $139(21.7 \%)$ \\
\hline$>27$ & $254(78.4 \%)$ & $247(77.7 \%)$ & $501(78.0 \%)$ \\
\hline \multicolumn{4}{|l|}{ HDL-cholesterol $(\mathrm{mmol} / \mathrm{L})$} \\
\hline Mean (SD) & $1.35(0.29)$ & $1.35(0.29)$ & $1.35(0.29)$ \\
\hline \multicolumn{4}{|c|}{ HDL-cholesterol group, $n(\%)$} \\
\hline M: $<1.036, F:<1.295$ & $100(30.9 \%)$ & $119(37.4 \%)$ & $219(34.1 \%)$ \\
\hline \multicolumn{4}{|l|}{ Triglycerides $(\mathrm{mmol} / \mathrm{L})$} \\
\hline Mean (SD) & $1.57(1.01)$ & $1.59(0.98)$ & $1.58(0.99)$ \\
\hline \multicolumn{4}{|l|}{ Triglycerides group, $n(\%)$} \\
\hline$\geq 1.69$ & $99(30.7 \%)$ & $101(31.9 \%)$ & $200(31.3 \%)$ \\
\hline \multicolumn{4}{|l|}{ LDL-cholesterol $(\mathrm{mmol} / \mathrm{L})$} \\
\hline Mean (SD) & $3.08(0.72)$ & $3.01(0.72)$ & $3.04(0.72)$ \\
\hline \multicolumn{4}{|c|}{ LDL-cholesterol group, $n(\%)$} \\
\hline$\geq 3.36$ & $113(34.9 \%)$ & $97(30.5 \%)$ & $210(32.7 \%)$ \\
\hline \multicolumn{4}{|l|}{ Total/HDL-cholesterol } \\
\hline Mean (SD) & $3.70(0.96)$ & $3.65(0.97)$ & $3.67(0.97)$ \\
\hline \multicolumn{4}{|l|}{ Fasting glucose $(\mathrm{mmol} / \mathrm{L})$} \\
\hline Mean (SD) & $5.07(0.48)$ & $5.17(0.56)$ & $5.12(0.52)$ \\
\hline \multicolumn{4}{|c|}{ Fasting glucose group, $n(\%)$} \\
\hline IFG: $\geq 5.55$ and $<6.99$ & $43(13.4 \%)$ & $68(21.5 \%)$ & $111(17.4 \%)$ \\
\hline Fasting insulin (pmol/L) & $92.04(57.41)$ & $98.30(158.08)$ & $95.17(118.8)$ \\
\hline \multicolumn{4}{|l|}{ Mean (SD) } \\
\hline \multicolumn{4}{|l|}{$H b A 1 c(\%)$} \\
\hline Mean (SD) & $5.56(0.39)$ & $5.61(0.41)$ & $5.59(0.40)$ \\
\hline
\end{tabular}

BMI: body mass index. HDL: high-density lipoprotein. IFG: impaired fasting glucose. LDL: low-density lipoprotein. HbAlc: glycosylated hemoglobin.

versus $4.3 \%)$, dyspepsia (3.1\% versus $0.6 \%)$, vomiting $(2.8 \%$ versus $0.9 \%$ ), dizziness ( $10.7 \%$ versus $9.6 \%)$, and depression ( $4.1 \%$ versus $0.9 \%)$.

\section{Discussion}

This 9-month RIO-Asia study showed that rimonabant $20 \mathrm{mg}$ is effective in reducing body weight in obese Asians. The 9-month treatment period with rimonabant was considered to be sufficient to compare the efficacy and safety of rimonabant with placebo, based on the results from previous RIO studies. A significantly greater reduction in weight was observed in the rimonabant 20-mg group compared with the placebo group $(-2.99 \mathrm{~kg}, P<.0001)$.
The percentage of patients who achieved at least 5\% (53.0\%) and $10 \%(20 \%)$ reduction of their baseline body weight with rimonabant treatment at 9 months was more than twice $(21.5 \%)$ and four times $(5.7 \%)$ compared with placebo. In obesity, a 5\% decrease in body weight is associated with an improved cardiometabolic profile [11].

The reduction in waist circumference followed the same pattern as body weight reduction. Obesity guidelines for Asia-Pacific have recommended a waist circumference of $\geq 90 \mathrm{~cm}$ in men and $\geq 80 \mathrm{~cm}$ in women [25]. Since rimonabant decreased the mean waist circumference by $2.8 \mathrm{~cm}$, reduction in abdominal obesity would also lower the risk of developing related metabolic disorders. International Day for the Evaluation of Obesity (IDEA) study established a graded 
TABLE 3: Change in weight (last observation carried forward) by BMI stratum in intent-to-treat population.

\begin{tabular}{|c|c|c|c|c|}
\hline \multirow[b]{2}{*}{ Weight (kg) } & \multicolumn{2}{|c|}{ BMI: 25 to $27 \mathrm{~kg} / \mathrm{m}^{2}$} & \multicolumn{2}{|c|}{ BMI: $>27 \mathrm{~kg} / \mathrm{m}^{2}$} \\
\hline & Placebo $(N=74)$ & Rimonabant $20 \mathrm{mg}(N=71)$ & Placebo $(N=251)$ & Rimonabant $20 \mathrm{mg}(N=247)$ \\
\hline \multicolumn{5}{|l|}{ Baseline } \\
\hline Mean (SD) & $67.42(6.21)$ & $69.28(7.45)$ & $86.19(16.22)$ & $84.23(14.81)$ \\
\hline \multicolumn{5}{|l|}{ Month 9 (LOCF) } \\
\hline Mean (SD) & $66.06(6.93)$ & $65.47(8.51)$ & $84.20(16.50)$ & $79.14(15.33)$ \\
\hline \multicolumn{5}{|l|}{ Change from baseline } \\
\hline Mean (SD) & $-1.37(2.95)$ & $-3.81(3.59)$ & $-1.99(4.55)$ & $-5.09(5.37)$ \\
\hline LS Mean (SEM) & $-1.35(0.384)$ & $-3.84(0.387)$ & $-2.02(0.315)$ & $-5.18(0.316)$ \\
\hline LS Mean Difference (SEM) & - & $-2.49(0.548)$ & - & $-3.16(0.446)$ \\
\hline $95 \% \mathrm{CI}$ & - & $(-3.570$ to -1.403$)$ & - & $(-4.034$ to -2.283$)$ \\
\hline$P$ value & - & $<.0001$ & - & $<.0001$ \\
\hline \multicolumn{5}{|l|}{ Percent change from baseline } \\
\hline Mean (SD) & $-2.05(4.58)$ & $-5.61(5.33)$ & $-2.31(4.94)$ & $-6.11(6.22)$ \\
\hline
\end{tabular}

BMI: body mass index. CI: confidence interval. LS: least square. LOCF: last observation carried forward.

TABLE 4: Most common adverse events ( $\geq 2 \%$ in rimonabant-treated patients and $\geq 1 \%$ in placebo).

\begin{tabular}{|c|c|c|}
\hline & Placebo $(N=324)$ & Rimonabant $(20 \mathrm{mg})(N=318)$ \\
\hline Patients with any TEAE & $184(56.8 \%)$ & $210(66.0 \%)$ \\
\hline Patients with any serious TEAE & $15(4.6 \%)$ & $10(3.1 \%)$ \\
\hline Patients with any TEAE leading to death & 0 & 0 \\
\hline Patients permanently discontinued due to TEAE & $9(2.8 \%)$ & $10(3.1 \%)$ \\
\hline \multicolumn{3}{|l|}{ Most common adverse events } \\
\hline \multicolumn{3}{|l|}{ Gastrointestinal disorders } \\
\hline Nausea & $13(4.0 \%)$ & $37(11.6 \%)$ \\
\hline Diarrhea & $14(4.3 \%)$ & $24(7.5 \%)$ \\
\hline Dyspepsia & $2(0.6 \%)$ & $10(3.1 \%)$ \\
\hline Vomiting & $3(0.9 \%)$ & $9(2.8 \%)$ \\
\hline \multicolumn{3}{|l|}{ Nervous system disorders } \\
\hline Dizziness & $31(9.6 \%)$ & $34(10.7 \%)$ \\
\hline \multicolumn{3}{|l|}{ Psychiatric disorders } \\
\hline Insomnia & $11(3.4 \%)$ & $14(4.4 \%)$ \\
\hline Depression & $3(0.9 \%)$ & $13(4.1 \%)$ \\
\hline Anxiety & $5(1.5 \%)$ & $12(3.8 \%)$ \\
\hline \multicolumn{3}{|l|}{ Skin and subcutaneous tissue disorders } \\
\hline Hyperhidrosis & $3(0.9 \%)$ & $7(2.2 \%)$ \\
\hline \multicolumn{3}{|l|}{ Cardiac disorders } \\
\hline Palpitations & $3(0.9 \%)$ & $15(4.7 \%)$ \\
\hline \multicolumn{3}{|l|}{ General disorders and administration site conditions } \\
\hline Fatigue & $3(0.9 \%)$ & $8(2.5 \%)$ \\
\hline \multicolumn{3}{|l|}{ Infections and infestations } \\
\hline URTI & $29(9.0 \%)$ & $34(10.7 \%)$ \\
\hline
\end{tabular}

TEAE: treatment-emergent adverse event; URTI: upper respiratory tract infection.

Note: TEAEs included all adverse events with an onset date during treatment exposure and up to 75 days following the last study drug intake.

relationship between waist circumference, diabetes mellitus, and cardiovascular disease [27].

Significant improvements in HDL-cholesterol and triglycerides, associated with the reduction in weight and waist circumference, were seen in the rimonabant $20 \mathrm{mg}$ group compared with the placebo group $(P<.001$, $P=.0047$, resp.). Hence, the results of this study indicate that treatment with rimonabant would have favourable effects on body weight and cardiometabolic risk profile in obese Asians who are known to have a greater incidence of obesity-related metabolic disorders at a lower BMI as compared with Caucasians [22].

The results in this RIO-Asia study are consistent with those in the 4 previous double-blind, placebo-controlled RIO studies (RIO-Lipids, RIO-Europe, RIO-Diabetes, and RIO-North America) conducted in more than 6000 patients, where rimonabant $20 \mathrm{mg}$ had shown a significant reduction in body weight at 1 year compared with placebo $(P<.001$ 


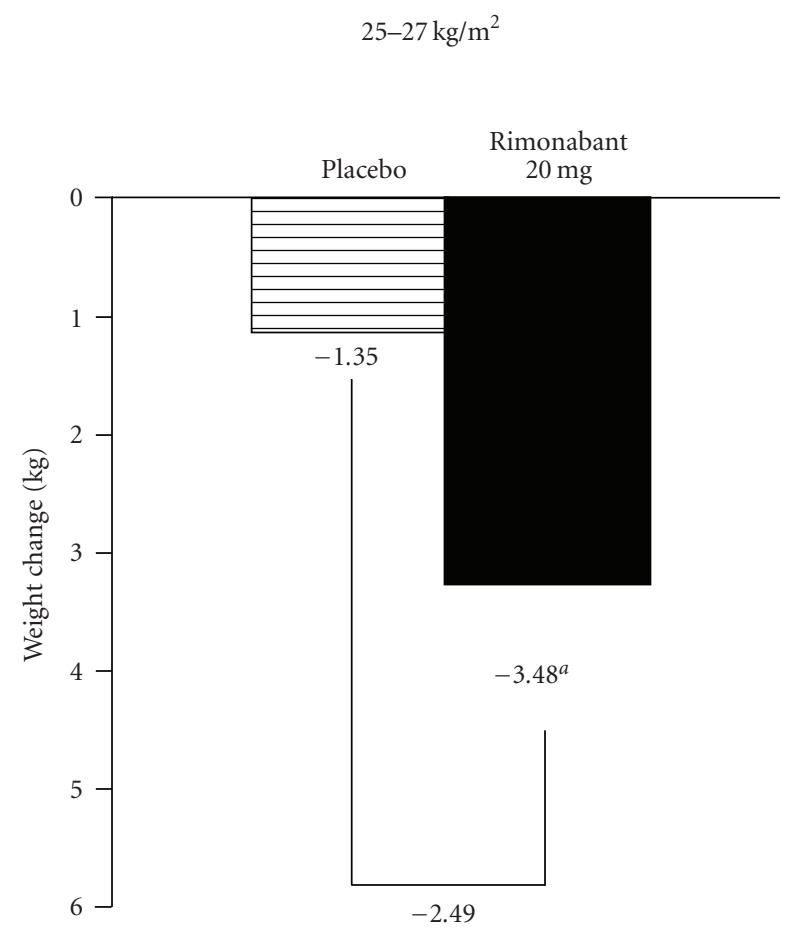

${ }^{\text {a }} P<.0001$ versus placepo

(a)

$>27 \mathrm{~kg} / \mathrm{m}^{2}$

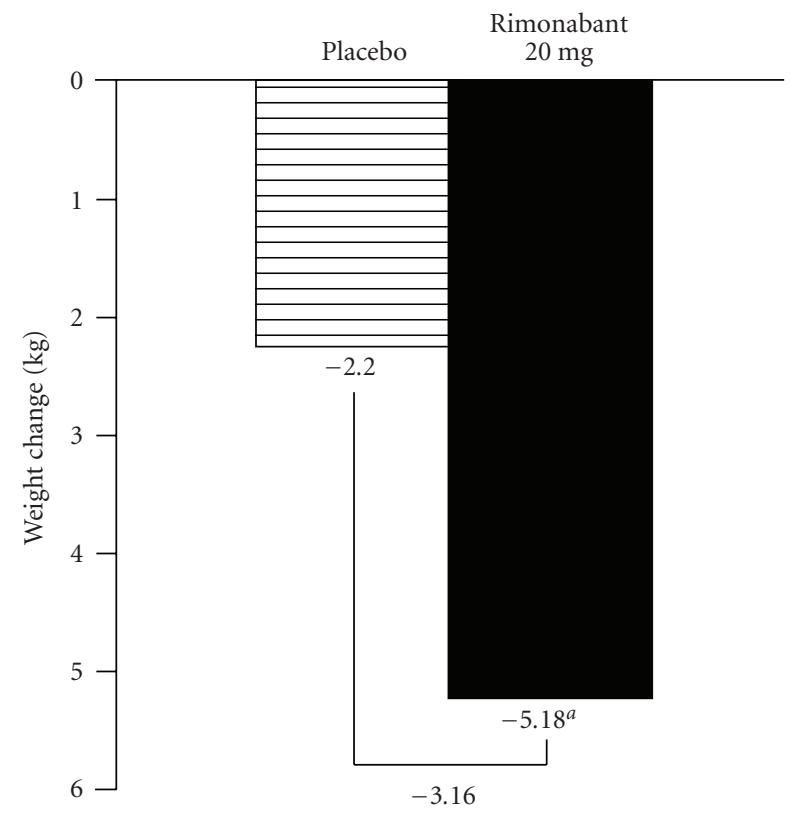

${ }^{\text {a }} P<.0001$ versus placepo

(b)

FIGURE 3: Changes in weight in intent to treat population stratified by BMI (last observation carried forward).

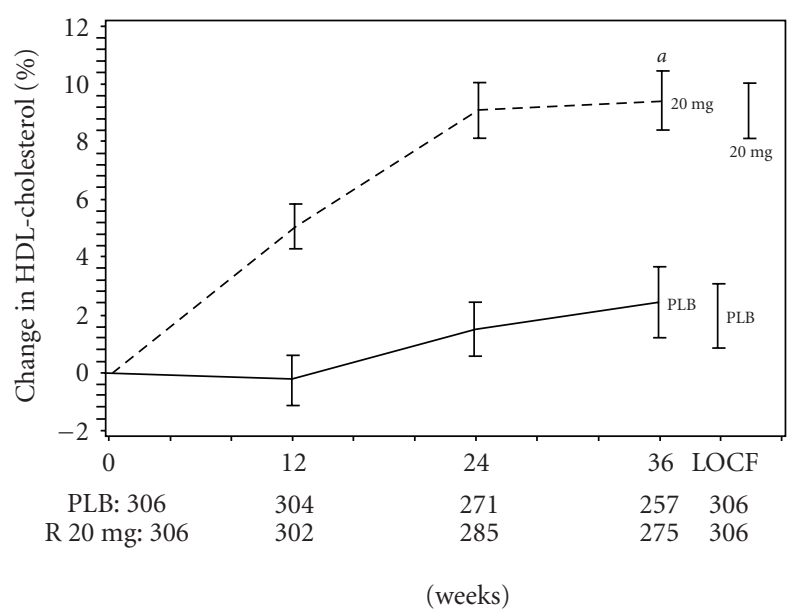

(a)

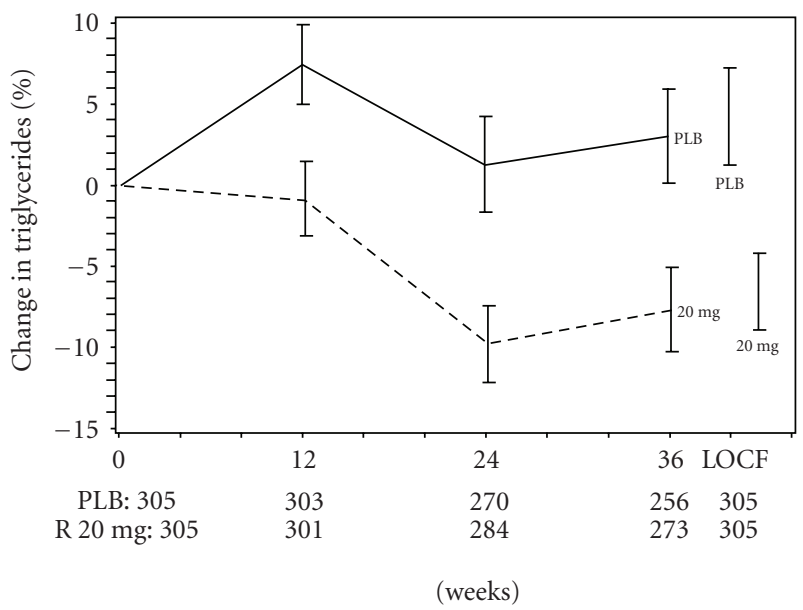

(b)

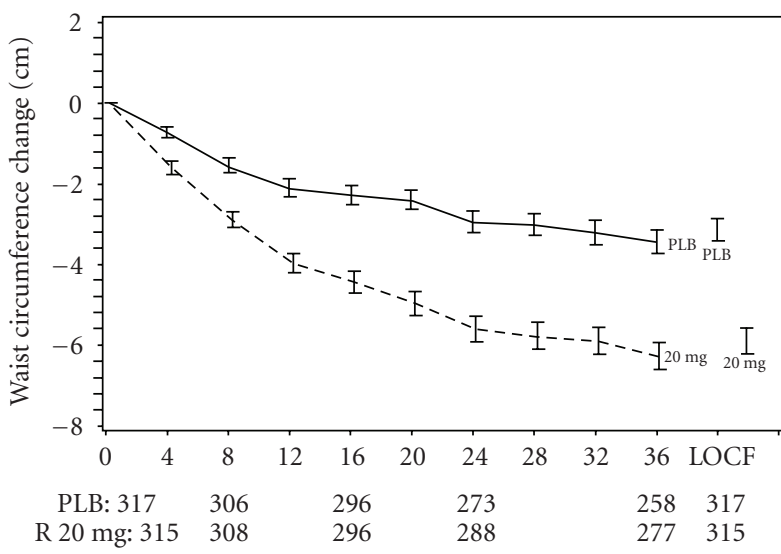

(weeks)

- Placebo

- - Rimonabant 20 mg

Error bars indicate standard error of mean.

${ }^{\mathrm{a}} P<.0001$ versus placebo.

PLB, placebo; R, Rimonabant;

LOCF, last observation carried forward.

(c)

FIGURE 4: Effect of rimonabant on HDL-cholesterol, triglycerides, and waist circumference at each visit and at 9 months. 
versus placebo). In Rio-Asia, the mean decrease in weight induced by rimonabant, compared with placebo, in the ITT population was $2.99 \mathrm{~kg}$ which was lower than RIONorth America $(5.2 \mathrm{~kg}$ ), RIO-Europe $(5.3 \mathrm{~kg})$, and RIOLipids $(6.0 \mathrm{~kg})$ on day 252 (data on file). The lower mean loss in body weight in the RIO-Asia study could be attributed to the lower baseline weights in Asian study population $(81.48 \mathrm{~kg})$ as compared with the Caucasian populations in the other studies $(93.2-102.7 \mathrm{~kg})$, but the percentage change in the weight loss was comparable among the different studies.

In this study, similar results for weight loss was observed across both BMI strata $\left(25-27 \mathrm{~kg} / \mathrm{m}^{2}\right.$ and $\left.>27 \mathrm{~kg} / \mathrm{m}^{2}\right)$. Rimonabant decreased weight by $5.61 \%$ in the group with a BMI 25 to $27 \mathrm{~kg} / \mathrm{m}^{2}$ and by $6.11 \%$ in the group with a BMI $>27 \mathrm{~kg} / \mathrm{m}^{2}$, which can lower the risk of developing related metabolic disorders. Metabolic disorders are initiated at a lower BMI in Asians compared with Caucasians [22]. The BMI cut-off points for overweight and obesity are different in the Asian population as compared with the Caucasian population $[1,22,25]$. In the IDEA study, which involved 177,345 patients in 63 countries, one half to two thirds of the study population were overweight or obese (BMI $\geq$ $25 \mathrm{~kg} / \mathrm{m}^{2}$ ). The frequency of diabetes mellitus and coronary vascular disease increased with waist circumference in all categories of BMI $\left(<25 \mathrm{~kg} / \mathrm{m}^{2}, 25-30 \mathrm{~kg} / \mathrm{m}^{2}\right.$, and $\left.>30 \mathrm{~kg} / \mathrm{m}^{2}\right)$ [27]. In adult Korean population, the incidence of diabetes, hypertension, and dyslipidemia was 2 times more at a BMI of 23.0 to $24.0 \mathrm{~kg} / \mathrm{m}^{2}$ and 3 times more at a BMI of $26.0 \mathrm{~kg} / \mathrm{m}^{2}$ [28]. In Chinese population, the inclination to accumulate truncal body fat is associated with metabolic complications, which occur at a lower BMI than in European/North American populations [21, 29].

Safety evaluation in this study found that rimonabant $20 \mathrm{mg}$ was generally well tolerated in the Asian study population. The most common adverse events reported with an incidence $\geq 2 \%$ in the rimonabant group were upper respiratory tract infection, nausea, diarrhea, dyspepsia, vomiting, dizziness, depression, anxiety, insomnia, hyperhidrosis, palpitations, and fatigue. In addition, a lower number of patients discontinued treatment due to adverse events and this number was comparable between the 2 treatment groups ( $3.1 \%$ versus $2.8 \%$, in rimonabant and placebo group, resp.). Among neuropsychiatric events, depression $(4.1 \%, n=13)$ and anxiety $(3.8 \%, n=12)$ were higher in the rimonabant $20 \mathrm{mg}$ compared to placebo $(0.9 \%, n=3$ and $1.5 \%, n=5)$. A meta-analysis of randomized trials involving rimonabant $20 \mathrm{mg} /$ day has proposed that rimonabant increases the risk of psychiatric adverse events including depression and anxiety. Patients were 2.5 and 3.0 times more likely to discontinue rimonabant due to depression and anxiety [30]. An overview of the RIO programme with rimonabant was published recently, which reviewed and summarized the overall efficacy and side effects of RIO trials including RIO-Europe, RIONorth America, RIO-Lipids, and RIO-Diabetes [31]. The vast majority of the test populations are western ethnics. The overall TEAE-induced drug discontinuation rate was higher in the rimonabant than the placebo groups either without (13.6\% versus $7.7 \%$, resp.) or with diabetes $(15.0 \%$ versus
$5.5 \%$, resp.). The reported $\mathrm{AE}$ of depression was increased in the rimonabant group, either in all obese cohort $(3.9 \%$ versus $1.7 \%$, resp.) or in diabetes programme $(2.5 \%$ versus $1.4 \%$, resp.). The TEAE-induced drug discontinuation rate in RIO-Asia seems to be much lower than that of other RIO trials. Although the RIO-Asia has relatively a smaller sample size and shorter duration than other RIO trials, the reported $\mathrm{AE}$ of depression rate is still significantly increased in the rimonabant group in Asian population. Hence, monitoring of rimonabant-induced psychiatric adverse events is essential.

The endocannabinoid system (ECS), encompassing endocannabinoids including anandamide and 2-arachidonoylglycerol (2-AG), two cannabinoid receptors, type 1 (CB1) and type 2 (CB2), and enzymes responsible for endogenous ligand synthesis (phospholipase D) and degradation (fatty acid amide hydrolase (FAAH)), is a complex physiological system involved in metabolic homeostasis such as modulating energy fluxes and nutrients regulation [32]. Recently, substantial clinical evidence revealed that $\mathrm{CB} 1$ antagonists might result in risks of severe psychiatric problems, including depression, anxiety, and stress disorders, especially in those with underlying or susceptible psychological problems. These findings have made rimonabant (SR14176A), the first CB1 inverse agonist approved and launched in Europe in 2006, withdrawn from the market in 2008, and thereof, several CB1 target-related candidates including taranabant (MK-0364) and otenabant (CP-945598) were suspended at the late clinical development stage (phase III). In the meanwhile, increased evidence indicates that $\mathrm{CB} 1$ receptors present in the peripheral tissue, including fat and liver, might regulate food intake and energy balance as effectively as those present in the central nervous system (CNS) [33]. This provides a rationale for development of peripherally preferred or restricted CB1 antagonists which possess minimized CNS adverse reactions and preserve antiobesity effects. Recently, this strategy of developing CB1 antagonists without penetrating blood-brain barrier (BBB) was found to meet with a certain degree of success. Sufficient weight-reduction efficacy and less CNS toxic profile have been observed with romonabant-mimicking analogues acting exclusively on peripheral CB1 receptors [34]. However, these compounds have been tested only in animals.

\section{Conclusion}

The RIO-ASIA study of 9-month duration confirmed the efficacy of rimonabant $20 \mathrm{mg}$ on weight reduction in the Asian population. Besides the favourable effect on weight, significant improvements were also observed in waist circumference, HDL-cholesterol, and triglycerides. The drug was associated with a good safety profile in the Asian study population, which was consistent with the pattern observed in the Caucasian population. However, in patients with a history of psychiatric disorder, especially those with a past history of depression, the usage of rimonabant is not recommended owing to mild yet considerable increase of 
psychiatric untoward side effects observed in this trial as well as other such similar trials. In addition, the psychiatric status of patients taking rimonabant has to be monitored regularly, preferably using a practical risk evaluation form such as the Columbia classification algorithm of suicide assessment (C-CASA) [35]. Perceptively, to avoid untoward CNS side effects in drug discovery for the intervention of the endocannabinoids system, an appealing strategy of development of peripherally restricted and highly CB1/CB2 selective antagonists may be desired. Some compounds of this kind have been shown to have promising results in lowering propensity to pass the blood-brain barrier with preserved weight-reducing effects in DIO mice [36, 37]. Another peripheral-acting CB1 neutral antagonist has been shown to have weight-independent effects on improving cardiometabolic risks and fatty liver in mouse models of obesity [38]. However, the clinical efficacy and safety of these new antiobesity compounds are yet to be seen.

\section{Conflict of Interests}

The authors declared no conflict of interests.

\section{Acknowledgments}

Dr. L. T. Ho acknowledges the assistance of Drs. C. F. Kwok, H. S. Chen, and S. C. Chiang for the RIO Asia study. This study was partly supported by a research Grant V97-C1-026 to Dr. Ho.

\section{References}

[1] "Global activity on diet, physical activity and health; obesity and overweight," WHO 2008, http://www.who.int/ dietphysicalactivity/publications/facts/obesity/en/.

[2] Y. Wu, "Overweight and obesity in China," British Medical Journal, vol. 333, no. 7564, pp. 362-363, 2006.

[3] N. F. Chu, "Prevalence of obesity in Taiwan," Obesity Reviews, vol. 6, no. 4, pp. 271-274, 2005.

[4] D. M. Kim, C. W. Ahn, and S. Y. Nam, "National prevalence of obesity: prevalence of obesity in Korea," Obesity Reviews, vol. 6, no. 2, pp. 117-121, 2005.

[5] A. W. Herling, S. Kilp, R. Elvert, G. Haschke, and W. Kramer, "Increased energy expenditure contributes more to the body weight-reducing effect of rimonabant than reduced food intake in candy-fed wistar rats," Endocrinology, vol. 149, no. 5, pp. 2557-2566, 2008.

[6] G. E. Sonnenberg, G. R. Krakower, and A. H. Kissebah, "A novel pathway to the manifestations of metabolic syndrome," Obesity Research, vol. 12, no. 2, pp. 180-186, 2004.

[7] P. Poirier, T. D. Giles, G. A. Bray et al., "Obesity and cardiovascular disease: pathophysiology, evaluation, and effect of weight loss," Arteriosclerosis, Thrombosis, and Vascular Biology, vol. 26, no. 5, pp. 968-976, 2006.

[8] H. Ohnishi, S. Saitoh, H. Akasaka et al., "Incidence of hypertension in individuals with abdominal obesity in a rural Japanese population: the Tanno and Sobetsu study," Hypertension Research, vol. 31, no. 7, pp. 1385-1390, 2008.
[9] A. N. Vgontzas, D. A. Papanicolaou, E. O. Bixler et al., "Sleep apnea and daytime sleepiness and fatigue: relation to visceral obesity, insulin resistance, and hypercytokinemia," Journal of Clinical Endocrinology and Metabolism, vol. 85, no. 3, pp. 1151-1158, 2000.

[10] H. J. Sun, E. Y. Ji, J. P. Eun et al., "Body mass index and cancer risk in Korean men and women," International Journal of Cancer, vol. 123, no. 8, pp. 1892-1896, 2008.

[11] F. Akbas, C. Gasteyger, A. Sjödin, A. Astrup, and T. M. Larsen, "A critical review of the cannabinoid receptor as a drug target for obesity management," Obesity Reviews, vol. 10, no. 1, pp. 58-67, 2009.

[12] K. A. Bronander and M. J. Bloch, "Potential role of the endocannabinoid receptor antagonist rimonabant in the management of cardiometabolic risk: a narrative review of available data," Vascular Health and Risk Management, vol. 3, no. 2, pp. 181-190, 2007.

[13] D. Shire, B. Calandra, M. Delpech et al., "Structural features of the central cannabinoid $\mathrm{CB} 1$ receptor involved in the binding of the specific CB1 antagonist SR 141716A," Journal of Biological Chemistry, vol. 271, no. 12, pp. 6941-6946, 1996.

[14] M. Bifulco, C. Grimaldi, P. Gazzerro, S. Pisanti, and A. Santoro, "Rimonabant: just an antiobesity drug? Current evidence on its pleiotropic effects," Molecular Pharmacology, vol. 71, no. 6, pp. 1445-1456, 2007.

[15] C. Quarta, L. Bellocchio, G. Mancini et al., “ $\mathrm{CB}(1)$ signaling in forebrain and sympathetic neurons is a key determinant of endocannabinoid actions on energy balance," Cell Metabolism, vol. 11, no. 4, pp. 273-285, 2010.

[16] M. Gary-Bobo, G. Elachouri, J. F. Gallas et al., "Rimonabant reduces obesity-associated hepatic steatosis and features of metabolic syndrome in obese zucker fa/fa rats," Hepatology, vol. 46, no. 1, pp. 122-129, 2007.

[17] V. Di Marzo, "The endocannabinoid system: its general strategy of action, tools for its pharmacological manipulation and potential therapeutic exploitation," Pharmacological Research, vol. 60, no. 2, pp. 77-84, 2009.

[18] L. F. Van Gaal, A. M. Rissanen, A. J. Scheen, O. Ziegler, and S. Rössner, "Effects of the cannabinoid-1 receptor blocker rimonabant on weight reduction and cardiovascular risk factors in overweight patients: 1-year experience from the RIO-Europe study," Lancet, vol. 365, no. 9468, pp. 1389-1397, 2005.

[19] F. X. Pi-Sunyer, L. J. Aronne, H. M. Heshmati, J. Devin, and J. Rosenstock, "Effect of rimonabant, a cannabinoid1 receptor blocker, on weight and cardiometabolic risk factors in overweight or obese patients-RIO-North America: a randomized controlled trial," Journal of the American Medical Association, vol. 295, no. 7, pp. 761-775, 2006.

[20] J. P. Després, A. Golay, and L. Sjöström, "Effects of rimonabant on metabolic risk factors in overweight patients with dyslipidemia," New England Journal of Medicine, vol. 353, no. 20, pp. 2121-2134, 2005.

[21] J. A. Levine, "Obesity in China: causes and solutions," Chinese Medical Journal, vol. 121, no. 11, pp. 1043-1050, 2008.

[22] Y. Kim, K. S. Youn, and H. Choi, "BMI and metabolic disorders in South Korean adults: 1998 Korea National Health and Nutrition Survey," Obesity Research, vol. 12, no. 3, pp. 445-453, 2004. 
[23] C. Barba, T. Cavalli-Sforza, J. Cutter et al., "Appropriate bodymass index for Asian populations and its implications for policy and intervention strategies," Lancet, vol. 363, no. 9403, pp. 157-163, 2004.

[24] C.-J. Chang, C.-H. Wu, C.-S. Chang et al., "Low body mass index but high percent body fat in Taiwanese subjects: implications of obesity cutoffs," International Journal of Obesity, vol. 27, no. 2, pp. 253-259, 2003.

[25] World Health Organization Western Pacific Region, International Association for the Study of Obesity and International Obesity Task Force, "The Asia-Pacific perspective: redefining obesity and its treatment," Australia: Health Communications Australia Pty Limited, 2000.

[26] K. van der Kooy and J. C. Seidell, "Techniques for the measurement of visceral fat: a practical guide," International Journal of Obesity, vol. 17, no. 4, pp. 187-196, 1993.

[27] B. Balkau, J. E. Deanfield, J. P. Després et al., "International day for the evaluation of abdominal obesity (IDEA): a study of waist circumference, cardiovascular disease, and diabetes mellitus in 168000 primary care patients in 63 countries," Circulation, vol. 116, no. 17, pp. 1942-1951, 2007.

[28] D. Gallagher, "Overweight and obesity BMI cut-offs and their relation to metabolic disorders in Koreans/Asians," Obesity Research, vol. 12, no. 3, pp. 440-441, 2004.

[29] W. H. Pan, K. M. Flegal, H. Y. Chang, W. T. Yeh, C. J. Yeh, and W. C. Lee, "Body mass index and obesity-related metabolic disorders in Taiwanese and US whites and blacks: implications for definitions of overweight and obesity for Asians," American Journal of Clinical Nutrition, vol. 79, no. 1, pp. 31-39, 2004.

[30] R. Christensen, P. K. Kristensen, E. M. Bartels, H. Bliddal, and A. Astrup, "Efficacy and safety of the weight-loss drug rimonabant: a meta-analysis of randomised trials," Lancet, vol. 370, no. 9600, pp. 1706-1713, 2007.

[31] A. J. Scheen, "CB1 receptor blockade and its impact on cardiometabolic risk factors: overview of the RIO programme with rimonabant," Journal of Neuroendocrinology, vol. 20, supplement 1, pp. 139-146, 2008.

[32] D. R. Janero and A. Makriyannis, "Cannabinoid receptor antagonists: pharmacological opportunities, clinical experience, and translational prognosis," Expert Opinion on Emerging Drugs, vol. 14, no. 1, pp. 43-65, 2009.

[33] M. A. Storr and K. A. Sharkey, "The endocannabinoid system and gut-brain signalling," Current Opinion in Pharmacology, vol. 7, no. 6, pp. 575-582, 2007.

[34] J. LoVerme, A. Duranti, A. Tontini et al., "Synthesis and characterization of a peripherally restricted CB cannabinoid antagonist, URB447, that reduces feeding and body-weight gain in mice," Bioorganic and Medicinal Chemistry Letters, vol. 19, no. 3, pp. 639-643, 2009.

[35] K. Posner, M. A. Oquendo, M. Gould, B. Stanley, and M. Davies, "Columbia Classification Algorithm of Suicide Assessment (C-CASA): classification of suicidal events in the FDA's pediatric suicidal risk analysis of antidepressants," American Journal of Psychiatry, vol. 164, no. 7, pp. 1035-1043, 2007.

[36] C. H. Wu, M. S. Hung, J. S. Song et al., "Discovery of 2-[5-(4-chloro-phenyl)-1-(2,4-dichloro-phenyl)-4-ethyl-1Hpyrazol-3-yl]-1,5,5-trimethyl-1,5-dihydro-imidazol-4-thione (BPR-890) via an active metabolite. A novel, potent and selective cannabinoid-1 receptor inverse agonist with high antiobesity efficacy in DIO mice," Journal of Medicinal Chemistry, vol. 52, no. 14, pp. 4496-4510, 2009.
[37] J. M. Receveur, A. Murray, J. M. Linget et al., "Conversion of 4cyanomethyl-pyrazole-3-carboxamides into CB1 antagonists with lowered propensity to pass the blood-brain-barrier," Bioorganic and Medicinal Chemistry Letters, vol. 20, no. 2, pp. 453-457, 2010.

[38] J. Tam, V. K. Vemuri, J. Liu et al., "Peripheral CB1 cannabinoid receptor blockade improves cardiometabolic risk in mouse models of obesity," Journal of Clinical Investigation, vol. 120, no. 8, pp. 2953-2966, 2010. 


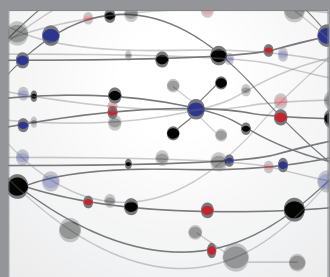

The Scientific World Journal
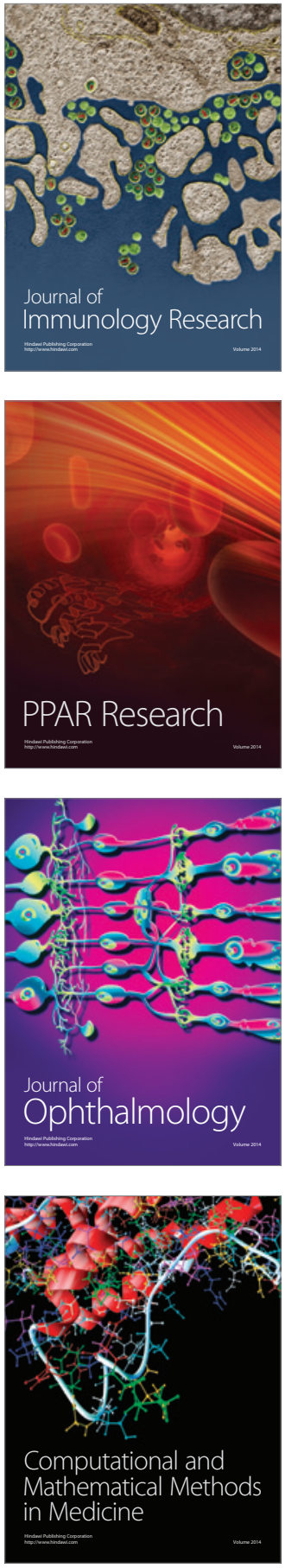

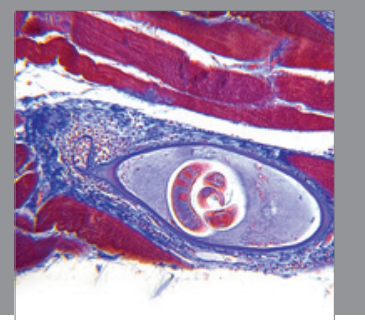

Gastroenterology

Research and Practice
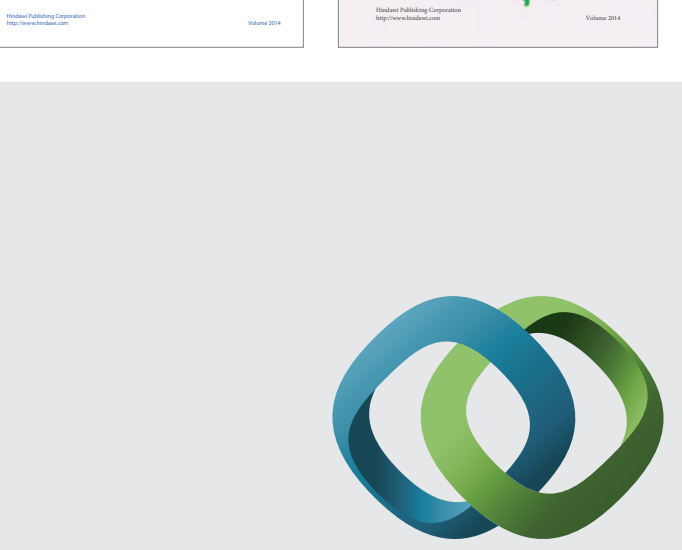

\section{Hindawi}

Submit your manuscripts at

http://www.hindawi.com
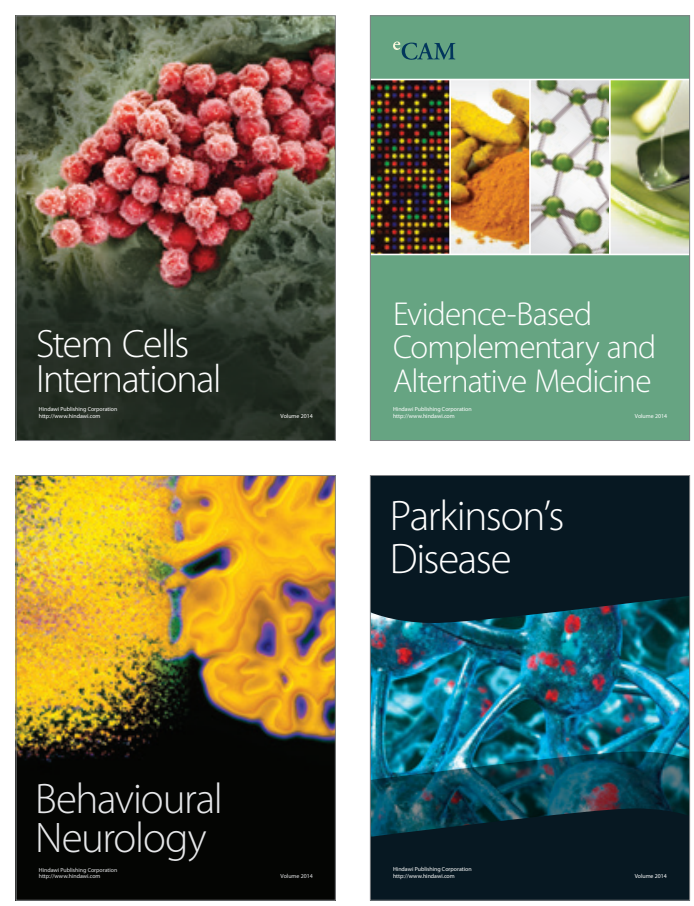

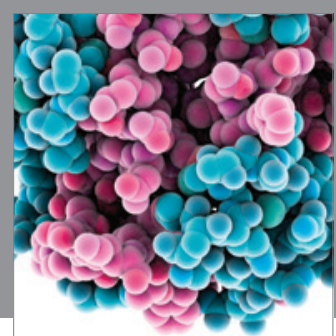

Journal of
Diabetes Research

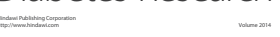

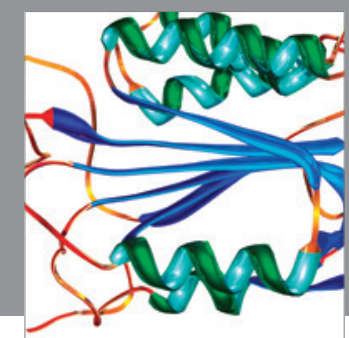

Disease Markers
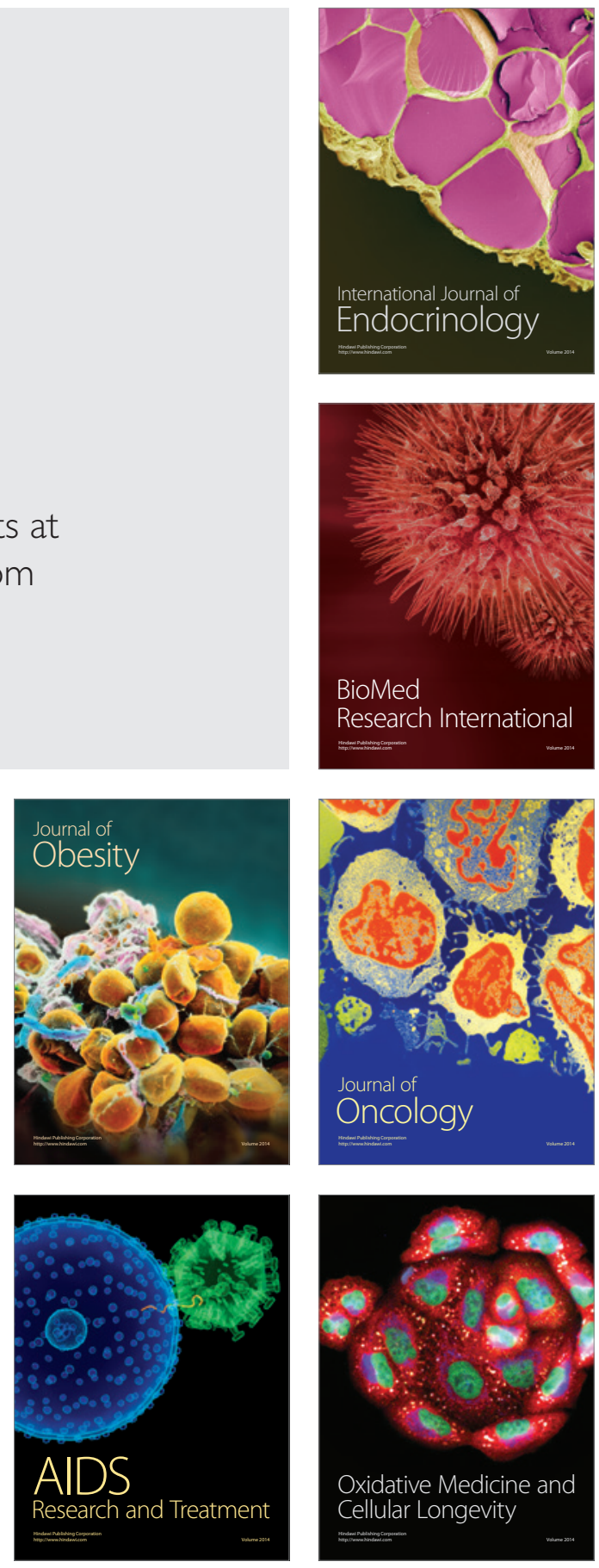